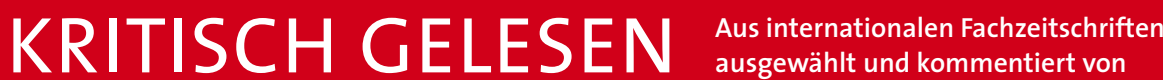

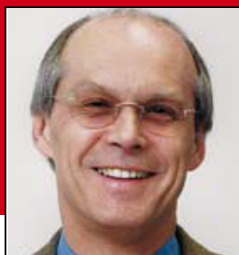

Prof. Dr. med. H. S. Füeß। Isar-AmperKlinikum, $\mathrm{Kl}$. MünchenOst, Haar

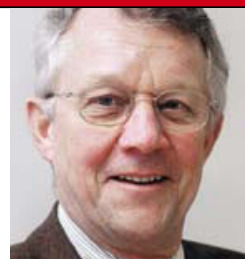

Prof. Dr. med. H. Holzgreve Internist, Kardiologische Praxis, München

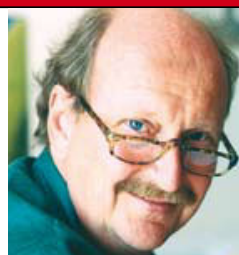

Prof. Dr. med.

E. Ernst

Peninsular

Medical School,

University of Exeter/UK

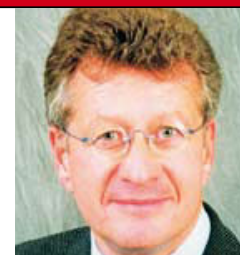

Dr. med. P. Stiefelhagen Westerwald Krankenhaus, Hachenburg

\section{Vorzeitiger Tod im Erwachsenenalter, der weltweite Trend}

\section{Die Bekämpfung der Säuglings- und Kindersterblichkeit seit 1980 hat zu bemerkenswerten Erfolgen geführt. In den Fokus der Gesundheitspolitik muss nun aber auch der vorzeitige Tod im Erwachsenenalter treten.}

- Die Autoren haben weltweit anhand von 3889 Datenbanken aus 187 Ländern die Mortalitätsraten zwischen dem 15. und 60. Lebensjahr eruiert. Naturgemäß schwanken die Zahlen ganz erheblich zwischen den einzelnen Ländern und im Verlauf zwischen 1980 und 2010 .

Weltweit haben die Todesfälle zwischen den 15 . und 60. Lebensjahr für Männer von 263 auf 200 und für Frauen von 210 auf 135/1000 Personen abgenommen. Die Sterblichkeit liegt für Männer höher als für Frauen. Dieser

\begin{tabular}{|lcc|}
\hline Tabelle 1 & & \\
\hline Weltweit & 1970 & 2010 \\
Männer & 263 & 200 \\
Frauen & 200 & 135 \\
Deutschland & & \\
Männer & 192 & 102 \\
Frauen & 109 & 54 \\
\hline
\end{tabular}

Todesfälle (pro 1000 Personen) zwischen dem 15. und 6o. Lebensjahr zwischen 1970 und 2010.

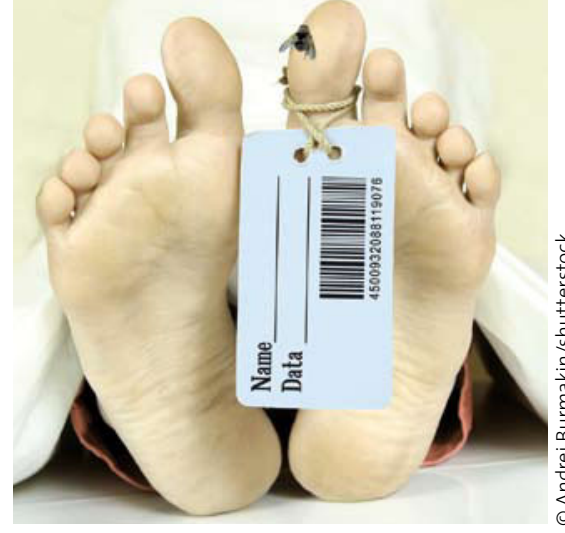

Unterschied hat sich zwischen 1970 und 2010 vergrößert. Die Zahlen für Deutschland gingen im genannten Zeitraum von 192 auf 102 für Männer und von 109 auf 54/1000 bei Frauen zurück und lagen damit deutlich unter dem weltweiten Mittelwert (s. Tab. 1). Entgegen dem weltweiten Trend ist die Mortalitätsrate zwischen 1970 und 2010 in Schwarzafrika infolge von HIV-Erkrankungen und in den ehemaligen Sowjetländern angestiegen.

Im Jahr 2010 hatten Island die niedrigste Mortalitätsrate für Männer $(65 / 1000)$ und Zypern für Frauen (38/1000). Die höchsten Raten finden sich in Swaziland für Männer (765/1000) und in Sambia für Frauen $(606 / 1000)$
4 Bei uns ist der vorzeitige Tod rückläufig, in der ehemaligen Sowjetunion und in Schwarzafrika wird er häufiger.

\section{Kommentar}

Seit 1980 zielten zahlreiche Bemühungen darauf $a b$, die Säuglings- und Kindersterblichkeit zu reduzieren. Tatsächlich ging die Sterblichkeit von Kindern unter fünf Jahren in den meisten Regionen deutlich zurück. Jetzt muss es gesundheitspolitisch auch darum gehen, vorzeitige Todesfälle im besten und produktivsten Lebensalter, d.h. zwischen dem 15. und 6o. Lebensjahr zu verhindern. Voraussetzung für alle $A k$ tivitäten weltweit agierender Organisationen sind zuverlässige Ausgangsdaten, die schwer zu erarbeiten sind, nachdem nur ca. 25\% der Weltbevölkerung in Ländern mit funktionierendem Meldesystem leben. Umso mehr haben die Autoren viel Lob für ihre innovative und sorgfältige Analyse verdient.

H. HolzG Reve =

\section{- J. K. Rajaratnam et al.}

Worldwide mortality in men and women aged $15-59$ years from 1970 to 2010 : a systematic analysis. New Engl. J. Med. 375 (2010) 1704-1720 